\title{
Infarma - Ciências Farmacêuticas: 30 anos divulgando conhecimento na área das Ciências Farmacêuticas.
}

\author{
Infarma - Pharmaceutical Sciences: 30 years disseminating the \\ knowlegment in the area of Pharmaceutical Sciences.
}

\author{
Anselmo Gomes de OLIVEIRA; \\ Dâmaris SILVEIRA \\ Editores-chefe
}

Com a conclusão do volume 30 (2018), o periódico Infarma - Ciências Farmacêuticas completou 30 anos de existência como um importante veículo de publicação científica oferecida pelo Conselho Federal de Farmácia. Contudo, a história de Infarma - Ciências Farmacêuticas vai além desses 30 anos.

A revista Infarma, nasceu como um informativo profissional do Conselho Federal de Farmácia, com o objetivo de integrar um processo de educação continuada que a Comissão de Ensino (Comensino) vinha articulando desde o início de 1992. O principal idealizador do projeto foi o Professor Pedro Ros Petrovick (UFRGS), o primeiro Presidente da Comissão Editorial, que contava também com os Professores Anselmo Gomes de Oliveira, João Ciribelli Guimarães, Nuno Alves Pereira e Roberto Eustáqui Righi. O primeiro número do volume $1 \mathrm{da}$ revista, foi publicado no bimestre julho-agosto de 1992, tendo como editorial o texto "O outro lado da face" de autoria de presidente do CFF Thiers Ferreira. Como colaboradores da edição estavam os Professores Tarcisio Palhano com o artigo "Orientação farmacêutica ao paciente", Seizi Oga "Interações medicamentosas", Valquíria Link Bassani e Teresa Cristinha Dalla Costa "Descongestionantes nasais," e Sheila Monteiro Lisboa e Maria de Lourdes Fernandes Valladão "Dispensação de cápsulas para emagrecer, uma abordagem dos aspectos legais”. Neste número também foi publicada uma crônica de Machado de Assis, de 1893 intitulada "Por que é que os remédios morrem".

Aquele início foi extremamente difícil, principalmente devido ao fato de que profissionais da área farmacêutica ainda não eram acostumados a escrever suas experiências profissionais. Então, durante algum tempo, Infarma publicava artigos de profissionais da área acadêmica, geralmente das Universidades, que eram convidados a contribuir. Outro fator dificultador era a disponibilização apenas da versão impressa da revista, visto que a informática estava apenas se inicializando no Brasil e as dificuldades de impressão e distribuição por postagem dos cerca de 25 mil exemplares se constituía num processo caríssimo para o CFF. Essas dificuldades foram vencidas com muito trabalho e articulação, porque não nos importava o tempo necessário para que Infarma se tornasse conhecida como um veículo de publicação disponível aos profissionais farmacêuticos para relatarem suas experiências, pois estávamos dispostos a tornar esse fato uma realidade.

A revista continuou com o formato clássico de diagramação e independência editorial até 1998, durante as gestões dos presidentes do CFF Thiers Ferreira, Gustavo Baptista Éboli, Arnaldo Zubioli e inicio da gestão de Jaldo de Souza Santos, embora a Comissão Editorial tenha sido desfeita, por motivo da organização estrutural do CFF, e suas atribuições sido passadas para a Comissão de Divulgação e Publicidade, conservando a composição. Nesse período, a revista foi deixando gradualmente sua característica principal de informativo profissional 
e integrando assuntos mais aproximados da pesquisa científica em todas as áreas das ciências farmacêuticas.

A partir de 1999, por razões financeiras, tanto da versão impressa quanto da postagem das revistas do CFF, houve uma modificação radical na estrutura das revistas Pharmácia Brasileira e Infarma, sendo que a segunda, embora continuasse com sua identidade editorial e característica científica, passou a ser veiculada como um encarte da primeira, perdendo parcialmente sua independência de periodicidade de publicação, pois foi necessário ajustar sua periodicidade com a periodicidade da primeira, que nem sempre era adequada, devido às características muito diferentes entre as duas publicações. Além disso, a Comissão de Divulgação e Publicidade foi desfeita, ficando a Revista isoladamente coordenada pelo Prof. Anselmo Gomes de Oliveira.

Foi uma época difícil, com entraves, com muitos erros decorrentes da situação da publicação se constituir em encarte de outra. Essa situação persistiu até o ano de 2012, quando no inicio da gestão da primeira diretoria presidida pelo atual presidente Walter da Silva Jorge João, foi tomada a decisão de tornar novamente a revista Infarma independente, introduzir também a versão on line (e-ISSN 2318-9312) com um pequeno número de fascículos impressos (ISSN 0104-0219). Assim, em 2012 foi realizada uma reestruturação, com a composição do corpo editorial e de avaliadores, com o convite a pesquisadores nacionais e estrangeiros, definição de novas regras e formatação para a publicação de artigos e periodicidade.

A estruturação definitiva deu-se a partir do primeiro número do ano de 2013 (v.25,n.1, 2013), quando Infarma teve o título alterado para Infarma-Ciências Farmacêuticas, contendo o editorial "Novos tempos, novos rumos" de autoria de seus editores-chefe Anselmo Gomes de Oliveira e Dâmaris Silveira. Na atualidade, além dos editores-chefe, o periódico conta com um editor adjunto e um grupo de editores associados de maioria das regiões de nosso país, além de um corpo editorial formado por cerca de 36 pesquisadores nacionais e internacionais. As reformulações estruturais foram exten- sas, introduzindo o Open Journal Systems (OJS) para o gerenciamento das submissões e acompanhamento das avaliações por pares, e a publicação dos artigos. Todo o conteúdo do periódico, desde o número 1 do volume 1 está disponibilizado on line. Para maior facilidade de identificação e busca dos artigos publicados, foi introduzido o DOI (Digital Object Identifier), o qual oferece a identificação e localização inequívoca de cada artigo publicado no periódico a partir de 2013. Evidentemente, o gerenciamento eletrônico de todo o processo editorial tem proporcionado maior agilidade e mobilidade, facilitado substancialmente a comunicação entre os editores-chefe e os editores associados e permitindo, aos autores, o acompanhamento em tempo real do processamento das submissões. O modelo de um volume anual com quatro números anuais e, eventualmente, suplementos, tem atendido a demanda de nossos autores colaboradores.

$\mathrm{Na}$ pessoa do atual Presidente do Conselho Federal de Farmácia Walter da Silva Jorge João devemos agradecer e ressaltar que durante esses 30 anos (e mais!) de existência do periódico Infarma - Ciências Farmacêuticas as diretorias que se sucederam na gestão do CFF sempre se dispuseram ao total apoio das atividades do periódico, conferindo aos editores total independência nas decisões editoriais e nos assuntos diversos relacionados com a implementação dos procedimentos necessários para o bom andamento do trabalho.

Para Infarma - Ciências Farmacêuticas, o primeiro trimestre de cada ano sempre foi marcado como um reinício. E agora, "reinicia" com o volume 31, 2019 de nosso periódico. Desde sua reestruturação global em 2013, os editores têm lutado incessantemente pela melhoria, tanto da qualidade editorial quanto da qualidade dos artigos que têm sido publicados. Ao concluirmos esse editorial gostaríamos agradecer aos nossos colaboradores e convidar nossos leitores para que visitem nosso site em http://revistas.cff. org.br/?journal=infarma, onde todo o acervo de Infarma - Ciências Farmacêuticas está disponível gratuitamente, e conheçam melhor a história da evolução deste importante veículo de divulgação científica e, particularmente, os artigos desse primeiro número do volume 31, de 2019. 